\title{
Eficiência de Interceptores de Esgoto sobre a Qualidade da Água: Uma Contribuição ao Planejamento Urbano Aplicado à Cidade de Jaboticabal-SP
}

\section{Sewer Collection Effectiveness on Water Quality: A Contribution to the Urban Planning Applied to Jaboticabal City - SP}

\section{BORGES, M. J. ${ }^{1,2,3}$, GALBIATTI, J. A. ${ }^{2,3}$, BENINCASA, M. ${ }^{2,3}$, MARQUES-JÚNIOR, J., ${ }^{2,3}$ e FERRAUDO, A. $\mathrm{S}^{3}$}

1 Prefeitura Municipal de Jaboticabal - SP

${ }^{2}$ Centro de Estudos Ambientais - CEA/UNESP

\section{Faculdade de Ciências Agrárias e Veterinárias - FCAV/UNESP}

\section{RESUMO}

Em áreas urbanas, um dos fatores ambientais de maior relevância em contribuir para a perda de qualidade de vida é o esgoto. Sendo inevitável a sua produção, comumente seu destino final são os cursos d'água. Isso determina que estudos e técnicas sejam desenvolvidos e devidamente aplicados, de modo a evitar sua influência nociva sobre a qualidade da água, tornando-a o mais próximo possível das condições naturais. A construção de interceptores de esgoto, ao longo de cursos d'água e seu posterior encaminhamento à estações de despoluição, constitui uma das técnicas mais recomendadas. Neste trabalho, procurou-se estudar a eficiência da aplicação desta técnica em restabelecer a qualidade da água em dois cursos que drenam a bacia hidrográfica na qual se insere a cidade de Jaboticabal-SP, Brasil. O estudo baseou-se na caracterização da bacia hidrográfica do Córrego Jaboticabal e do seu afluente, Córrego Cerradinho, e da qualidade da água, a partir de amostras coletadas mensalmente durante um ano, ao longo de seus cursos, tanto na área urbana, quanto na área rural - próximo às nascentes, à montante da área urbana e após a confluência dos dois córregos, à jusante da área urbana. Os principais aspectos analisados foram: temperatura, $\mathrm{pH}, \mathrm{OD}, \mathrm{DQO}$, nitrito, nitrato, $\mathrm{N}_{\text {Total }}, \mathrm{P}_{\text {Total }}, \mathrm{DBO}$, coliformes totais e coliformes fecais (Escherichia coli). Para avaliar 
o efeito desses parâmetros nas estações de amostragem, foram utilizadas as análises de agrupamento e de componentes principais. Os resultados da pesquisa permitiram concluir que em ambos os córregos houve aumento da poluição hídrica da nascente à foz e que a prática isolada de saneamento (coleta de esgoto urbano com aplicação de interceptores) melhorou a qualidade da água mas não foi suficiente para despoluir estes córregos.

Palavras-chave: bacia hidrográfica, poluição, contaminação, saneamento básico.

\section{ABSTRACT}

The sewer is one of the most relevant environmental factors which contributes to loss of life quality in the urban areas. Usually, the sewer final destiny is in the watercourse-bound, since it's production is inevitable. It demands studies and techniques to be developed and duly applied so that its harmful influence on water quality is avoid, making it as close as possible of its natural conditions. The construction of sewer collection throughout watercourses and its further forwarding to the sewer treatment stations have been considered the most recommended technique. In this study we tried to analise the effectiveness of the application of this technique to reestablish the water quality in two watercourses which drain the river basin where Jaboticabal city is placed. The study was based in Cerradinho and Jaboticabal streams and in water quality characterization. The samples of the water were collected monthly during a year, throughout the watercourses, both in the urban and in the rural areas - near the headwater, in the urban area upstream and after the confluence of both, at the urban area downstream. The main aspects, which were analyzed, were the following: temperature, $\mathrm{pH}, \mathrm{DO}, \mathrm{COD}$, nitrite, nitrate, total-N, total-P, BOD, total coliforms and fecal coliforms (Escherichia coli). Analyses of cluster and main components were used to evaluate the effect of hidrical parameters in the collect stations. The results of the research showed that there was increase of hidrical pollution from the riverhead to the outfall of Cerradinho and Jaboticabal streams and that the isolated practices of sanitation (collection of the urban sewer) improved the water quality but it was not enough to return these streams to the non polluted condition.

Keywords: watershed, pollution, contamination, basic sanitation.

\section{INTRODUÇÃO}

O desenvolvimento tecnológico nas últimas décadas, tem exigido maior utilização dos recursos naturais, cujo consumo estima-se que ultrapassou a capacidade de renovação da biosfera. No tocante aos recursos hídricos, seja no meio urbano ou rural, o crescimento demográfico e a expansão das atividades econômicas são causas do aumento 
das demandas e de sua deterioração (PINTO, 1998). Esse recurso mineral renovável pode se tornar exaurível, pois a quantidade excessiva de poluentes nas águas pressiona sua capacidade de absorção e regeneração a níveis que impedem sua recuperação (LANDIM, 1997).

Alterações na quantidade, distribuição e qualidade dos recursos hídricos, ameaçam a sobrevivência humana e demais espécies do planeta, estando o desenvolvimento econômico e social dos países fundamentado na disponibilidade de água de boa qualidade e na capacidade de sua conservação e proteção. Conforme relata TUNDISI (1999), o gerenciamento inadequado pode comprometer os recursos hídricos como ocorreu na região do Mar de Aral na Ásia Central, onde o desenvolvimento de um megaprojeto de irrigação alterou o ciclo hidrológico e a salinização do solo, com reflexo negativo na saúde humana, sendo difícil a solução a médio prazo.

Substâncias tóxicas e compostos sintéticos na água podem causar no organismo humano, aumento da incidência de: câncer, defeito congênito, alterações genética e neurológica e danos aos sistemas nervoso, endócrino e imunológico (BATALHA, 1998).

Exposição a produtos de tratamento da água de abastecimento, podem ser associados a doenças. Os compostos orgânicos voláteis podem provocar leucemia; o cloro, o alumínio e o flúor podem causar respectivamente câncer, demência da diálise e fluorose (BATALHA, 1998); o ozônio pode induzir efeitos mutagênicos (GRASSI \& JARDIM, 1993).

A água pode ser um veículo de transmissão de agentes (bactérias, protozoários, vírus e outros) causadores de doenças infecciosas e parasitárias. A contaminação humana pode ocorrer pela ingestão ou contato com a água contaminada por esses agentes, ou pode estar associada a doenças cujos agentes utilizam a água como meio de multiplicação ou local obrigatório de estágio no ciclo de vida (MOTA, 1993).

A maioria dos municípios brasileiros captam água de cursos superficiais para o abastecimento e nestes descarregam os efluentes domésticos e industriais, provocando aumento na extensão dos trechos poluídos e interferindo na diluição sofrida pelos contaminantes contidos nos efluentes e na capacidade natural dos cursos d'água em receber quantidades e tipos diferentes de carga poluidora (CAMARGO, 1997).

A contaminação por carga poluidora depende da vulnerabilidade do aqǘfero e do tipo, quantidade e maneira como o contaminante é depositado no ambiente. $\mathrm{O}$ sistema público de tratamento da água (sedimentação, filtração e desinfecção), clarifica a água e elimina organismos causadores de doenças agudas, porém dificilmente remove as micro quantidades de compostos tóxicos de origem química ou biológica que podem acumular no organismo do consumidor (BATALHA, 1998). 
O tratamento de esgoto sanitário deve corrigir características indesejáveis como sólidos em suspensão, material orgânico biodegradável, nutrientes $(\mathrm{P}$ e $\mathrm{N})$ e organismos patogênicos, para que o seu uso ou disposição final ocorra de acordo com regras e critérios definidos. PALMA-SILVA (1999) demonstrou que o efluente de uma Estação de Tratamento de Esgoto, quando atinge o rio provoca, à jusante, alterações de vários parâmetros, como fosfatos, nitrito, demanda química de oxigênio (DQO), coliformes totais $(\mathrm{CT})$ e coliformes fecais $(\mathrm{CF})$.

Analisando o esgoto bruto e o efluente final do sistema de tratamento da água residuária urbana do município de Rio Claro-SP, DAMASCENO \& CAMPOS (2000) identificaram que o sistema de tratamento na forma de lagoa de estabilização foi eficiente na remoção de DQO, demanda bioquímica de oxigênio (DBO) e CF, apresentando considerável potencial para ser utilizado no setor agrícola, na forma de fertirrigação.

A bacia hidrográfica, no ambiente por ela definido, é a área ideal para o planejamento integrado do manejo dos recursos naturais, sendo que no Estado de São Paulo as ações tem sido descentralizadas mediante a criação de áreas formadas por uma ou mais sub-bacias hidrográficas (SECRETARIA DE ESTADO DO MEIO AMBIENTE, 1997).

Diretrizes e normas foram estabelecidas para o uso múltiplo dos mananciais, considerando necessário implementar medidas de: preservação e recuperação dos aqüíferos; recomposição da mata ciliar; controle das fontes poluidoras; tratamento dos efluentes domésticos e industriais; e controle sobre os agroecossistemas. A qualidade hídrica do corpo d'água varia com o tempo e seu diagnóstico exige análise periódica e avaliação integrada de variáveis físicas, químicas, biológicas e toxicológicas. As amostras devem ser submetidas a exames laboratoriais utilizando-se parâmetros internacionais da Organização Mundial da Saúde e aceitos pelo Ministério da Saúde com algumas restrições quanto a valores máximos permitidos (GIOMETTI, 1998).

O objetivo deste trabalho foi avaliar a qualidade da água e a eficiência da implantação de interceptores de esgoto dos córregos Cerradinho e Jaboticabal, os quais drenam a bacia hidrográfica na qual se insere a cidade de Jaboticabal-SP, Brasil.

\section{MATERIAL E MÉTODOS}

A área de estudo está inserida na bacia hidrográfica do Córrego Jaboticabal (Figura 1), município de Jaboticabal, região Nordeste do Estado de São Paulo, posição geográfica $21^{\circ} 15^{\prime} 22^{\prime \prime}$ latitude sul e $48^{\circ} 18^{\prime} 58^{\prime \prime}$ longitude WG e população do município de 67.129 habitantes, dos quais $90,3 \%$ residem na cidade (INSTITUTO BRASILEIRO DE GEOGRAFIA E ESTATÍSTICA, 2000). Essa bacia hidrográfica domina a região 
representada pelas áreas da cidade e da Faculdade de Ciências Agrárias e Veterinárias da Universidade Estadual Paulista - FCAV/UNESP (BENINCASA, 1971); é sub-bacia do Córrego Rico, afluente do Rio Mogi-Guaçu, cuja bacia hidrográfica corresponde à $9^{\mathrm{a}}$ Unidade de Gerenciamento de Recursos Hídricos (SECRETARIA DE ESTADO DE RECURSOS HÍDRICOS SANEAMENTO E OBRAS, 1998).

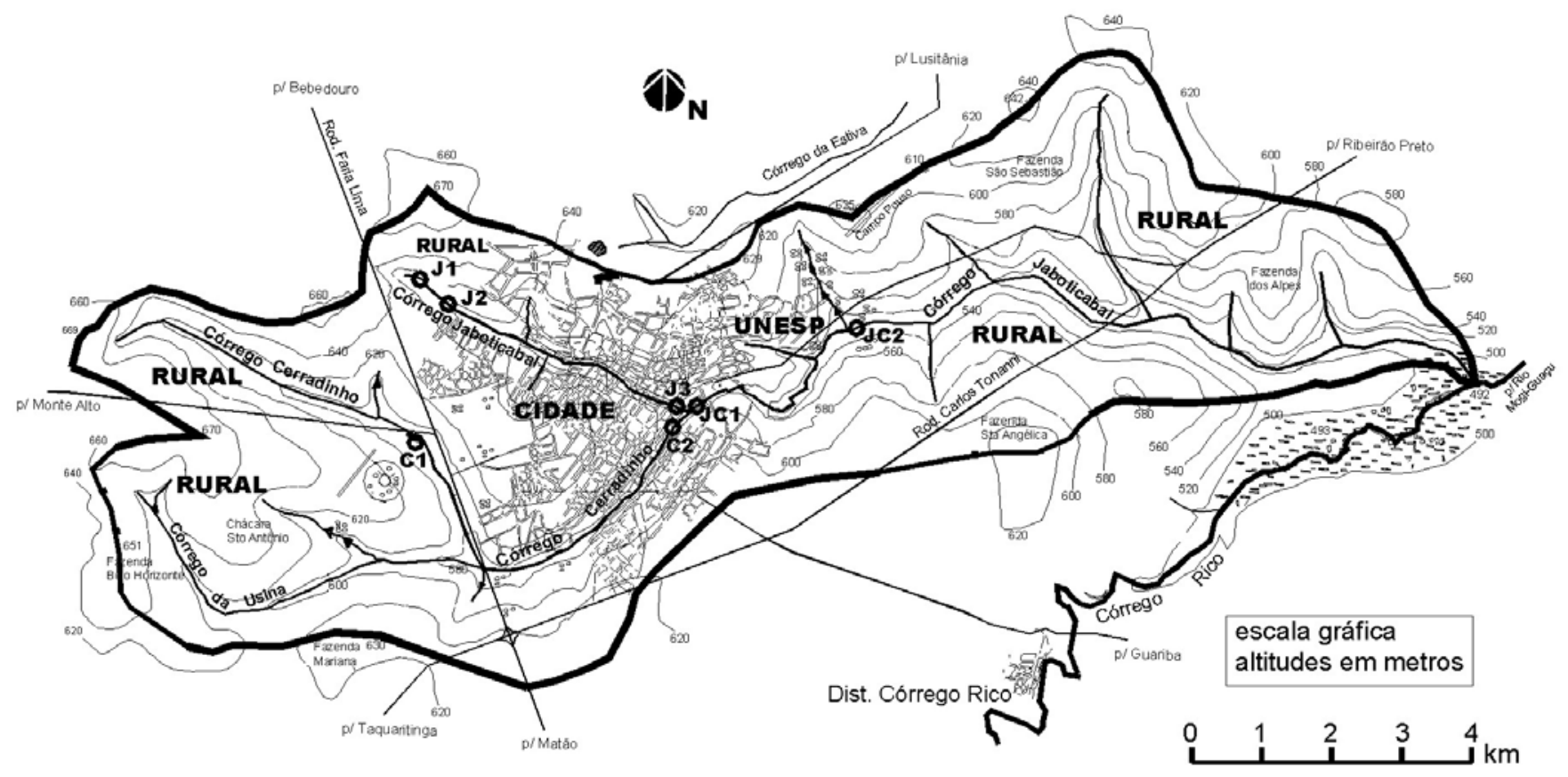

Legenda

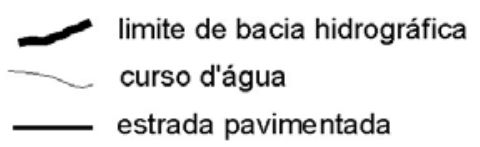

área inundável

J1 um parâmetro acima da Classe 3

C1 dois parâmetros acima da Classe 3
C2 e JC1 três parâmetros acima da Classe 3

$\mathbf{J} 2$ e J3 quatro parâmetros acima da Classe 3

JC2 cinco parâmetros acima da Classe 3

Click na Figura para Ampliar

Figura 1. Mapa da classificação das estações de amostragem e cursos d'água estudados nos córregos Cerradinho e Jaboticabal, em função dos parâmetros analisados de maio/1999 a abril/2000, conforme Resolução CONAMA 20/86 (Fonte da escala: INSTITUTO GEOGRÁFICO E CARTOGRÁFICO, 1991).

O município de Jaboticabal apresenta clima "Cwa" (classificação de Köeppen), sendo a temperatura média mensal máxima $23,6^{\circ} \mathrm{C}$ (janeiro) e mínima $17,7^{\circ} \mathrm{C}$ (julho), a precipitação média anual $1.428 \mathrm{~mm}$, o excedente hídrico médio anual $452 \mathrm{~mm}$ e a deficiência hídrica média anual 34mm (CENTURION, 1998); dezembro e janeiro são os meses mais úmidos e julho e agosto os mais secos (JABOTICABAL, 1999).

A formação vegetal primária desse município é do tipo floresta latifoliada tropical, formada basicamente por ecossistemas da Floresta Atlântica e trechos de cerrado (JOLLY, 1970). Do total da área rural, 91,7\% é usada com agricultura, 6,3\% são Áreas 
de Preservação Permanente e apenas $2,0 \%$ são fragmentos florestais. A vegetação atual predominante é a cana-de-açúcar (VALERI \& MENEZES, 2000).

As unidades de solos predominantes na Bacia Hidrográfica do Córrego Jaboticabal são os Latossolos Vermelhos (LV); os LV que ocorrem à montante da cidade são solos com horizonte $\mathrm{A}$ moderado distrófico com textura média relevo plano e suavemente ondulado e os LV à jusante são solos com horizonte A moderado distroférrico e proeminente com textura argilosa relevo suave ondulado e plano. Esses solos correspondem, respectivamente, ao Latossolo Vermelho-Escuro e ao Latossolo Roxo, na antiga classificação de solos.

Os córregos Cerradinho e Jaboticabal são perenes, classificados como reto para meandro encaixado e o fluxo normal de água é do tipo turbulento corrente com um pequeno trecho encachoeirado (afloramento de rocha basáltica entre cidade e FCAV/UNESP). À montante da cidade e à jusante da FCAV/UNESP, esses córregos recebem influência rural de erosão do solo, prática agrícola (defensivo e adubo), criação de animais, área de lazer e piscicultura. Na área urbana, a influência maior é de: esgoto doméstico, entulho, escoamento superficial, produto químico e animal doméstico. $\mathrm{Na}$ FCAV/UNESP a ação é tanto urbana quanto rural, diminuindo a contribuição por esgoto doméstico e edificações, porém aumentando a de criação, tanque de piscicultura, produto de laboratório e erosão do solo.

Quando do início da amostragem em maio/1999, os interceptores de esgoto urbano da cidade de Jaboticabal já estavam em operação no Córrego Cerradinho, enquanto que no Córrego Jaboticabal só foi concluído em julho/1999. Todo o esgoto coletado é direcionado ao Córrego Jaboticabal próximo do trecho encachoeirado à jusante da cidade e à montante da FCAV/UNESP.

As estações de amostragem de água (Tabela 1 e Figura 1) foram definidas em função da viabilidade de acesso ao local e a possibilidade de se caracterizar três seguimentos de cursos d'água: 1) o Córrego Cerradinho da área rural (C1) até próximo da confluência com o Córrego Jaboticabal (C2); 2) o Córrego Jaboticabal da nascente (J1) até próximo da confluência com o Córrego Cerradinho (J3); 3) o Córrego Jaboticabal da confluência dos dois córregos (JC1) à FCAV/UNESP (JC2).

Tabela 1. Localização das estações de amostragem de água, nos córregos Cerradinho e Jaboticabal, Jaboticabal-SP

\begin{tabular}{|c|c|c|c|c|}
\hline Estação & Curso d'água & \begin{tabular}{|} 
Distância \\
da \\
nascente
\end{tabular} & $\begin{array}{c}\text { Altitude } \\
(\text { cota }) \\
(\mathrm{m})\end{array}$ & Localização \\
\hline
\end{tabular}




\begin{tabular}{|c|c|c|c|c|}
\hline & & $(\mathrm{km})$ & & \\
\hline $\mathrm{C} 1$ & Cerradinho & 4,7 & 590 & $\begin{array}{l}\text { Rural, ponte } \\
\text { Lafranchi }\end{array}$ \\
\hline $\mathrm{C} 2$ & Cerradinho & 10,6 & 560 & $\begin{array}{l}\text { Urbana, ponte } \\
\text { Trabalhadores }\end{array}$ \\
\hline $\mathrm{J} 1$ & Jaboticabal & 0,5 & 618 & Rural, bebedouro \\
\hline $\mathrm{J} 2$ & Jaboticabal & 1,3 & 607 & $\begin{array}{l}\text { Rural/Urbana, } \\
\text { ponte CDHU* }\end{array}$ \\
\hline $\mathrm{J} 3$ & Jaboticabal & 4,5 & 558 & $\begin{array}{l}\text { Urbana, ponte } \\
\text { Tiradentes }\end{array}$ \\
\hline $\mathrm{JC} 1$ & Jaboticabal/Cerradinho & 5,1 & 556 & $\begin{array}{l}\text { Urbana, lago } \\
\text { municipal }\end{array}$ \\
\hline $\mathrm{JC} 2$ & Jaboticabal/Cerradinho & 8,3 & 531 & $\begin{array}{l}\text { Rural, ponte } \\
\text { FCAV/UNESP** }\end{array}$ \\
\hline
\end{tabular}

* Companhia de Desenvolvimento Habitacional e Urbano

** Faculdade de Ciências Agrárias e Veterinárias da Universidade Estadual Paulista

As amostras de água foram colhidas mensalmente no período de maio/1999 a abril/2000, de quarta a sexta-feira, evitando dias com chuva. As amostras consistiram da água superficial retirada do ponto mais central possível, acondicionada em frascos com capacidade de até 1 litro, abertos no momento da amostragem e fechados a seguir. Após transporte para o laboratório as amostras foram analisadas conforme metodologia recomendada por AMERICAN PUBLIC HEALTH ASSOCIATION (1995).

Dos parâmetros analisados nesta pesquisa, os que são contemplados na classificação das águas determinadas pela Resolução CONAMA 20/86 (CONSELHO NACIONAL DO MEIO AMBIENTE, 1986), apresentam para as Classes de 1 à 4 os limites constantes da Tabela 2.

Tabela 2. Valores limites de parâmetros de qualidade hídrica em função da classificação das águas determinada pela Resolução CONAMA 20/86

\begin{tabular}{||c||c||c||c||c||}
\hline Parâmetro & Classe 4 & Classe 3 & Classe 2 & Classe 1 \\
\hline \hline
\end{tabular}




\begin{tabular}{|c|c|c|c|c|}
\hline $\mathrm{OD}\left(\mathrm{mg} \cdot \mathrm{L}^{-1}\right)$ & $\begin{array}{c}\text { superior } \\
\text { a } 2\end{array}$ & $\begin{array}{c}\text { não } \\
\text { inferior a } \\
4\end{array}$ & $\begin{array}{c}\text { não } \\
\text { inferior a } \\
5\end{array}$ & $\begin{array}{c}\text { não } \\
\text { inferior a } \\
6\end{array}$ \\
\hline $\mathrm{pH}$ & 4 a 9 & 4 a 9 & 4 a 9 & 4 a 9 \\
\hline$P_{\text {total }}\left(m g . L^{-1}\right)$ & --- & até 0,025 & até 0,025 & até 0,025 \\
\hline Nitrato (mg. $\left.\mathrm{L}^{-1}\right)$ & --- & 10 & 10 & 10 \\
\hline Nitrito $\left(m g . L^{-1}\right)$ & --- & 1 & 1 & 1 \\
\hline $\begin{array}{l}\text { Coliforme total } \\
\left(\mathrm{NMP} .100 \mathrm{~mL}^{-1}\right)\end{array}$ & --- & até 20.000 & até 5.000 & até 1.000 \\
\hline $\begin{array}{l}\text { Coliforme fecal } \\
\left(\mathrm{NMP} .100 \mathrm{~mL}^{-1}\right)\end{array}$ & --- & até 4.000 & até 1.000 & até 200 \\
\hline $\begin{array}{l}\mathrm{DBO}_{5} \text { a } 20^{\circ} \mathrm{C}\left(\mathrm{mg} \cdot \mathrm{L}^{-}\right. \\
\left.{ }^{-}\right)\end{array}$ & --- & até 10 & até 5 & até 3 \\
\hline
\end{tabular}

$\mathrm{O}$ parâmetro físico temperatura foi mensurado no próprio local da amostragem através da leitura direta em termômetro de mercúrio (MATHEUS et al., 1995). Os parâmetros químicos e biológicos foram analisados em laboratório, sendo o $\mathrm{pH}$ através da leitura em potenciômetro digital (BRAILE \& CAVALCANTI, 1979); o oxogênio dissolvido (OD) pelo método Winkler modificado pela azida sódica, a DBO a partir da diferença do OD mensurado em uma amostra no início e ao final do período de 5 dias de incubação e a DQO, o nitrato e o nitrito mediante leituras em espectrofotômetro digital HACH DR/2000 (ADAMS, 1990 e AMERICAN PUBLIC HEALTH ASSOCIATION, 1995); para o $\mathrm{N}_{\text {total }}$ e o $\mathrm{P}_{\text {total }}$, obteve-se inicialmente alíquotas das amostras, nas quais foram empregadas, respectivamente, os métodos titulométrico e colorimétrico (MALAVOLTA et al., 1989); e os exames bacteriológicos de CT e CF (Escherichia coli) pela Técnica de Substratos Definidos empregando o produto comercial Colilert, na forma preconizada pela AMERICAN PUBLIC HEALTH ASSOCIATION (1995).

Para avaliar o efeito dos parâmetros de qualidade da água, foram realizadas análises multivariadas de Agrupamento e de Componentes Principais, sendo as variáveis $\left(\mathbf{X}_{\mathbf{i}}, \mathrm{i}=1\right.$ a 11) submetidas à transformação: 


$$
Z_{i}=\frac{x_{i}-\bar{x}_{i}}{s} \text {, onde: }
$$

$Z_{i}=$ variável $X_{i}$ transformada

$\bar{x}_{i}=$ média da variável $X_{i}$

$\mathrm{s}_{\mathrm{i}}=$ desvio padrão da variável $\mathrm{X}_{\mathrm{i}}$

A análise de agrupamento pode ser entendida como uma série de métodos desenvolvidos para analisar um único conjunto de dados com o objetivo de encontrar grupos de unidades operacionais (OTU's) ou de variáveis que tenham máxima homogeneidade intra-grupos e máxima heterogeneidade entre grupos, permitindo a elaboração de dendrogramas ilustrativos (SNEATH \& SOKAL, 1973). O software "Statistics for Windows", versão 5.1, foi utilizado para a aplicação da Análise de Agrupamento. As OTU's foram as sete estações de amostragem e as variáveis consideradas foram: temperatura, $\mathrm{pH}, \mathrm{OD}, \mathrm{DQO}, \mathrm{N}_{\text {total }}, \mathrm{P}_{\text {total }}$, nitrito, nitrato, $\mathrm{DBO}, \mathrm{CT}$ e CF. A estratégia de agrupamento adotada foi "Average Linkage" e o coeficiente de semelhança a distância euclidiana média.

A análise de componentes principais foi realizada com auxílio do "software" "SAS System for Windows Release", versão 6.12. Esta desenvolve novos vetores denominados componentes principais (CP1 e CP2) que são combinações lineares das variáveis em estudo. Tais vetores procuram explicar a estrutura das variâncias e covariâncias. A correlação entre cada variável e o componente principal mostra a importância da variável na classificação.

\section{RESULTADOS E DISCUSSÃO}

\section{Situação e Similaridade Hídrica nas Estações de Amostragem}

Nas Figuras 2 e 3, pode-se observar que da nascente à foz, a tendência é de: aumento da DQO, $\mathrm{P}_{\text {total' }} \mathrm{N}_{\text {total }}$, DBO, CT e CF; aumento com posterior oscilação do nitrato e nitrito; aumento com posterior estabilidade de temperatura e $\mathrm{pH}$; estabilidade e posterior diminuição do OD. 


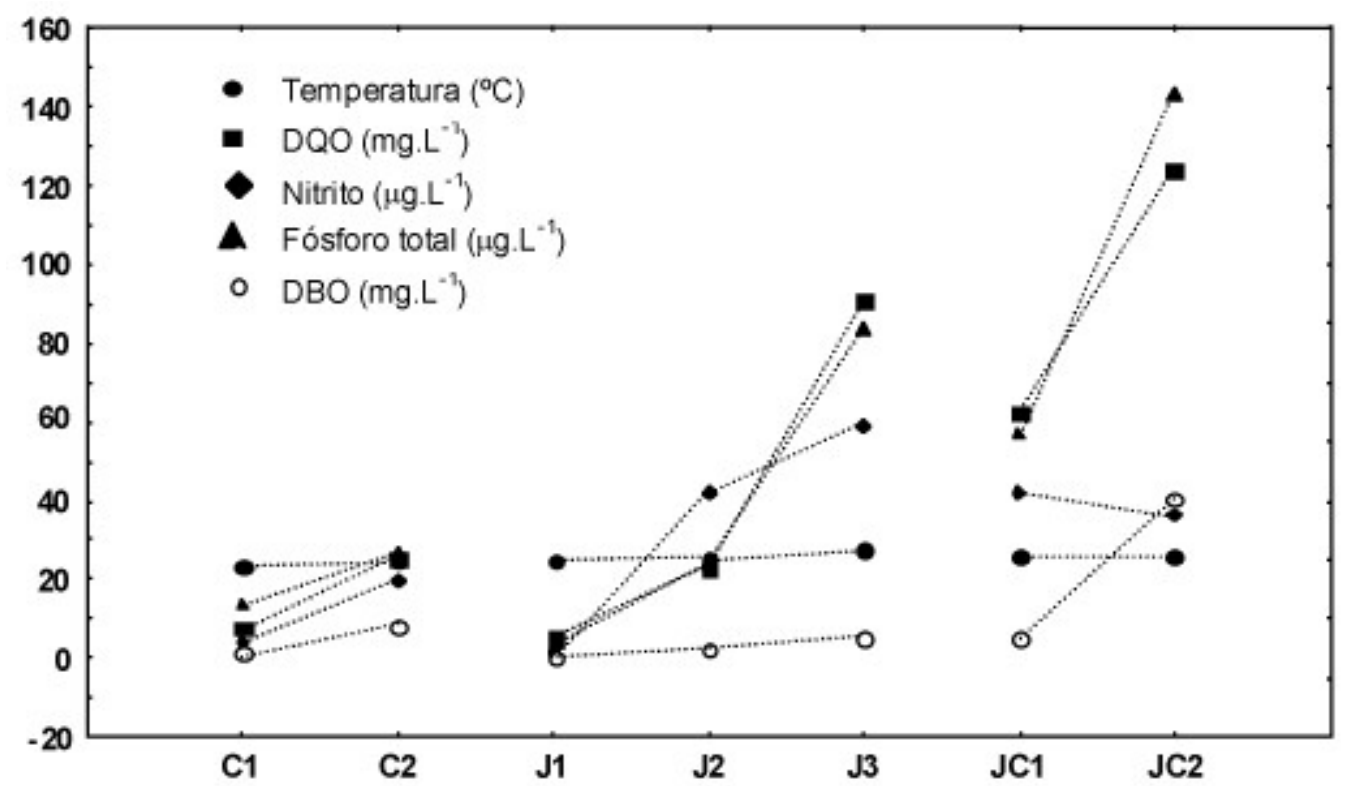

Figura 2. Valores médios de temperatura e teores médios de DQO, nitrito, fósforo total e DBO na água colhida nas estações dos córregos Cerradinho (C1-C2) e Jaboticabal (J1-J2J3 e JC1-JC2), de maio/1999 a abril/2000, Jaboticabal-SP.

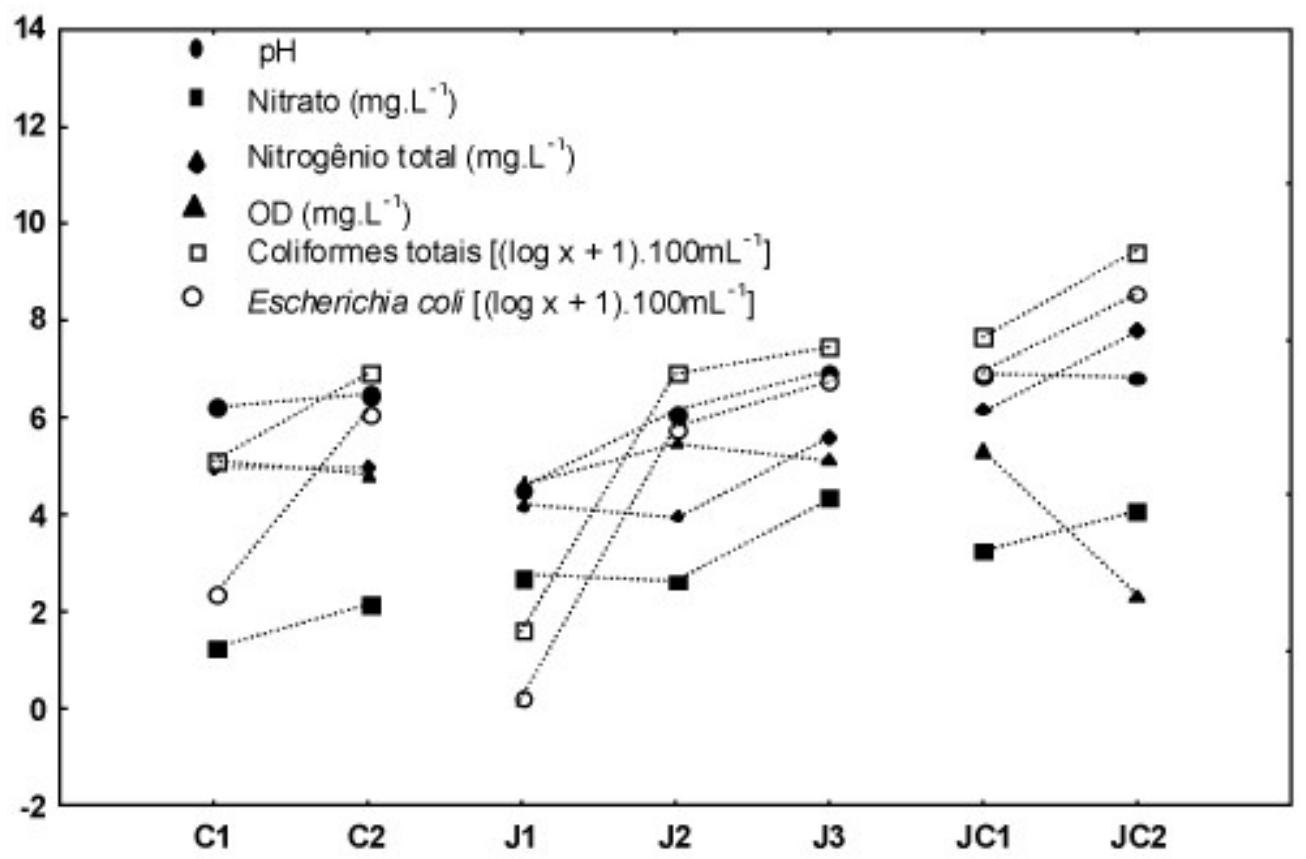

Figura 3. Valores médios $\mathrm{pH}$, teores médios de nitrato, nitrogênio total, OD e NMP de coliformes totais e coliformes fecais (Escherichia coli) na água amostrada dos córregos Cerradinho (C1-C2) e Jaboticabal (J1-J2-J3 e JC1-JC2), de maio/1999 a abril/2000, Jaboticabal-SP.

De uma maneira geral, os valores dos parâmetros analisados nas estações, obedeceram a seguinte ordem crescente: $\mathrm{J} 1$; C1; C2 e J2; J3 e JC1; e finalmente JC2. 
No dendrograma da análise de agrupamento (Figura 4) e na distribuição das estações da análise de componentes principais (Figura 5), verifica-se a formação de dois grupos de estações similares: um grupo com as estações $\mathrm{J} 2, \mathrm{C} 2$ e $\mathrm{C} 1$, e outro com as JC1 e J3. As estações J1 e JC2 não apresentam similaridade nem entre si e nem com as demais, sendo que a não similaridade se deve a forte ação antrópica poluidora nas águas do Córrego Jaboticabal: a J1 é considerada como isenta de ação antrópica direta e a JC2 como a que recebe a maior deterioração proveniente das áreas urbanizadas.

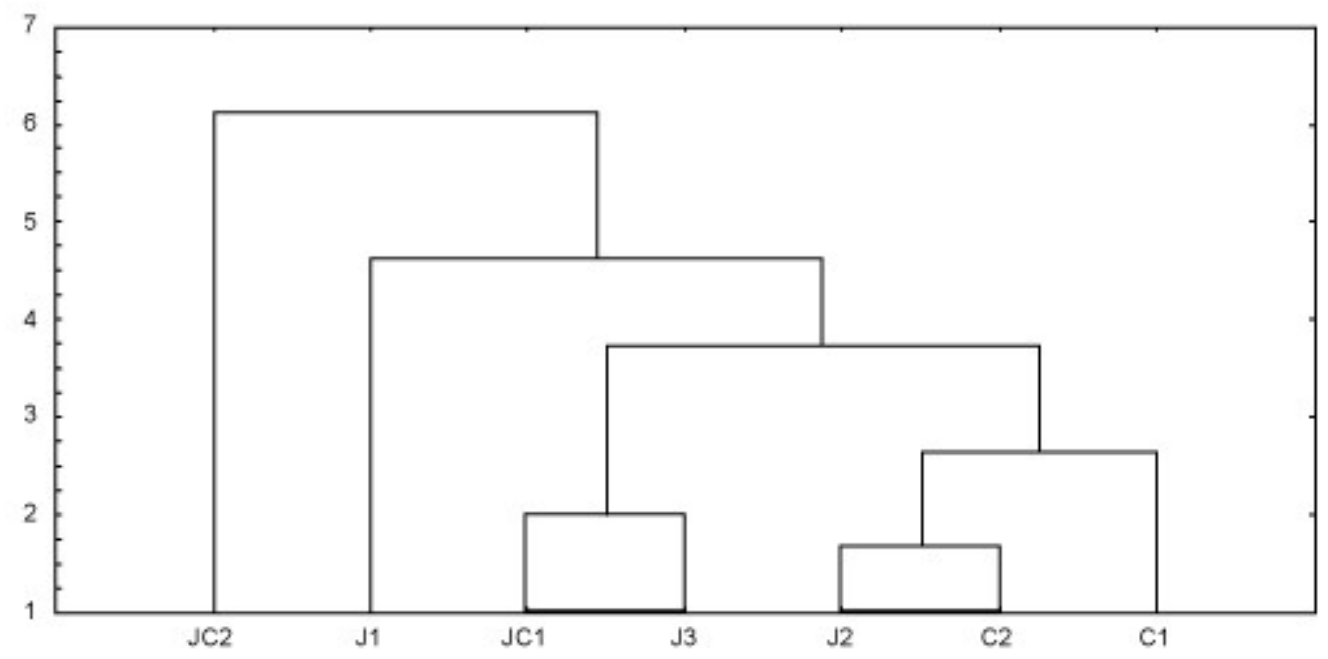

Figura 4. Dendrograma da similaridade entre as estações de amostragem dos córregos Cerradinho (C1-C2) e Jaboticabal (J1-J2-J3 e JC1-JC2), em relação aos parâmetros hídricos de temperatura, $\mathrm{pH}, \mathrm{OD}, \mathrm{DQO}$, nitrato, nitrito, $\mathrm{N}_{\text {total }}, \mathrm{P}_{\text {total }}$, DBO, coliformes totais e coliformes fecais (Escherichia coli), de maio/1999 a abril/2000, Jaboticabal-SP. 


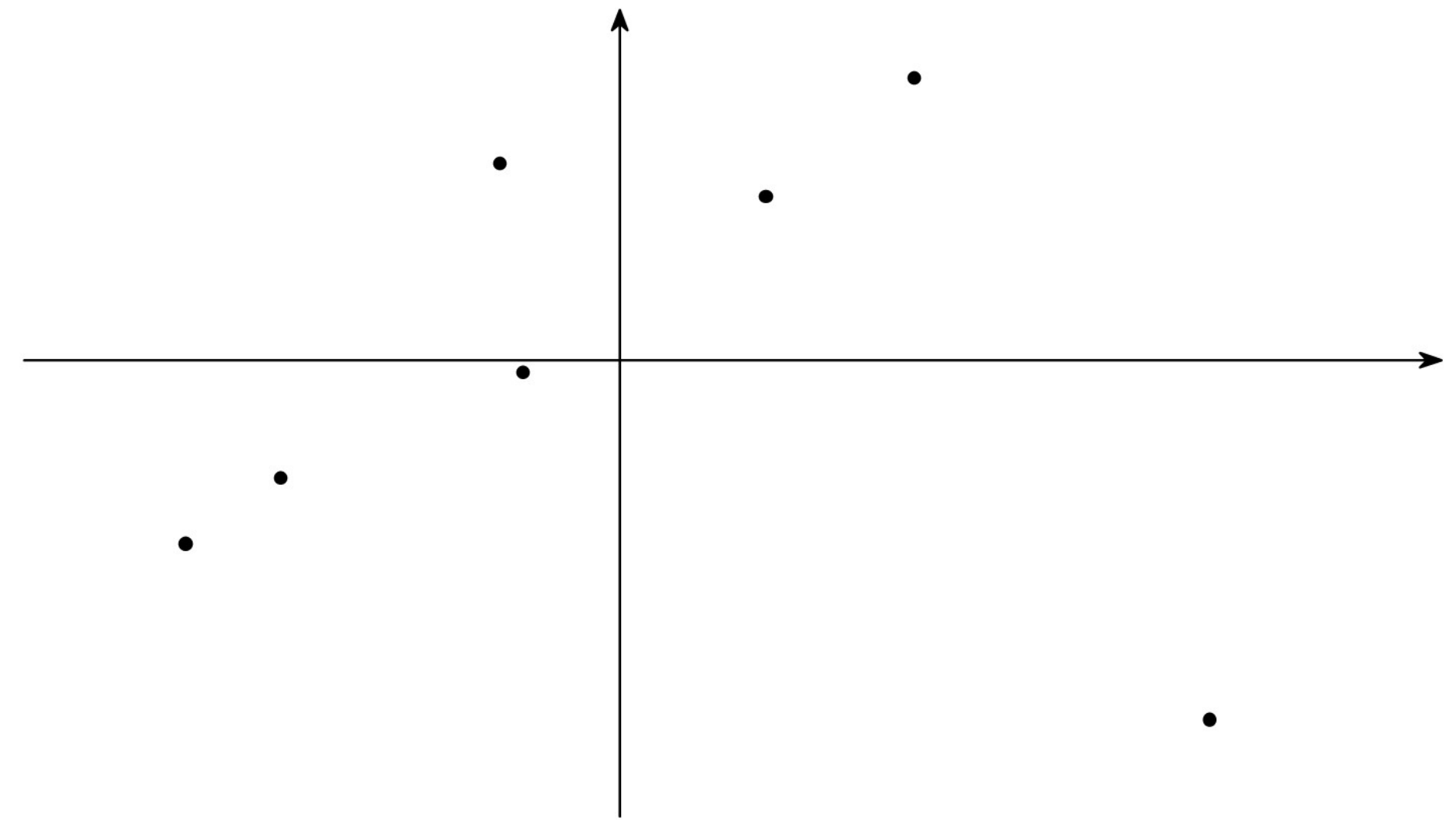

Figura 5. Dispersão das estações de amostragem dos córregos Cerradinho (C1-C2) e Jaboticabal (J1-J2-J3 e JC1-JC2), em relação a dois primeiros componentes principais (CP1 e CP2), de maio/1999 a abril/2000, Jaboticabal-SP.

Na Figura 5, o componente principal 1 (CP1) pode ser considerado um gradiente de poluição. A estação J1 na extremidade esquerda desse gradiente é explicada pela ausência de ação antrópica direta; na $\mathrm{C} 1$ a poluição é devido à ação inadequada de práticas agrícolas, criação de animais e áreas de lazer; na J2 e C2 a presença de efluente urbano aumenta a poluição, porém a contribuição de esgoto orgânico é baixa causada pela presença dos coletores às margens dos córregos; na $\mathrm{JC} 1$ e $\mathrm{J} 3$ a emissão de esgoto orgânico nas águas do Córrego Jaboticabal de maio a julho, foi o responsável pela elevação dos valores médios dos parâmetros. Por sua vez a JC2 encontra-se na extremidade direita no CP1 por receber forte ação antrópica urbanizada da cidade e da FCAV/UNESP, incrementada a partir de agosto pela transferência do local de despejo do esgoto urbano, o qual deixou de ser descartado ao longo do Córrego Jaboticabal em área urbana para ser despejado à montante do JC2.

A Tabela 3 mostra a importância de cada variável segundo os dois componentes principais, sendo que o componente principal CP1 retém 69,21\% da variação total e o CP2 retém $18,44 \%$. As variáveis que mais contribuíram para a formação dos agrupamentos seguem ordenação decrescente: $\mathrm{P}_{\text {total }}, \mathrm{DQO}, \mathrm{CF}, \mathrm{N}_{\text {total }}$ ' $\mathrm{DBO}$, nitrito, $\mathrm{CT}$, temperatura, $\mathrm{pH}$, nitrato e OD. 
Tabela 3. Análise dos componentes principais ( $\mathrm{CP} 1$ e $\mathrm{CP} 2)$, utilizando-se as variáveis dimensionais que contribuíram para os agrupamentos, analisados nas amostras de água dos córregos Cerradinho e Jaboticabal, de maio/1999 a abril/2000, Jaboticabal-SP

\begin{tabular}{|c|c|c|c|c|}
\hline Variável & CP1 & $\mathrm{CP} 2$ & & $\begin{array}{l}\text { Ordem de } \\
\text { importância }\end{array}$ \\
\hline $\mathrm{P}_{\text {total }}$ & 0,9670 & $-0,2186$ & 0,810 & 1 \\
\hline DQO & 0,9793 & $-0,0845$ & 0,791 & 2 \\
\hline $\begin{array}{l}\text { CF (Escherichia } \\
\text { coli) }\end{array}$ & 0,9086 & 0,2170 & 0,763 & 3 \\
\hline $\mathrm{N}_{\text {total }}$ & 0,8616 & $-0,3856$ & 0,762 & 4 \\
\hline DBO & 0,7776 & $-0,6046$ & 0,741 & 5 \\
\hline Nitrito & 0,7570 & 0,6279 & 0,730 & 6 \\
\hline CT & 0,8811 & 0,1614 & 0,730 & 7 \\
\hline Temperatura & 0,7773 & 0,4738 & 0,714 & 8 \\
\hline $\mathrm{pH}$ & 0,7738 & 0,3335 & 0,681 & 9 \\
\hline Nitrato & 0,8093 & 0,1471 & 0,670 & 10 \\
\hline OD & $-0,5820$ & 0,7965 & 0,627 & 11 \\
\hline \% Variação & 69,21 & 18,44 & & \\
\hline \% Variação total & \multicolumn{2}{|c|}{87,64} & & \\
\hline
\end{tabular}

Os resultados mostram que variáveis básicas são eficazes na identificação e no monitoramento de corpos d'água alterados por descargas de esgotos orgânicos. Para MARGALEF (1983) o uso de variáveis com altos valores de correlações no CP1, indica que a medição de uma variável altamente correlacionada com outras é suficiente para diagnosticar ambientes alterados. Essa análise é coerente com os resultados obtidos por CAMARGO et al. (1995) e PALMA-SILVA (1999) ao avaliarem o impacto provocado pelas descargas de esgotos orgânicos em alguns corpos d'água do município de Rio Claro-SP.

Estes resultados mostram afinal que os interceptores de esgoto contribuíram para a melhoria da qualidade da água dos córregos Cerradinho e Jaboticabal, mas não o suficiente para considerá-los despoluídos, estando, ainda, distantes das condições ideais de potabilidade ou de uso mais exigente. 


\section{Classificação das Águas dos Córregos Cerradinho e Jaboticabal}

De acordo com a Resolução CONAMA 20/86, a CETESB (1994) classificou o Córrego Jaboticabal como sendo de Classe 4, o que permite que suas águas sejam destinadas a navegação, à harmonia paisagística e aos usos menos exigentes.

Os valores dos parâmetros de qualidade da água analisados foram comparados aos determinados pela Resolução CONAMA 20/86, permitindo identificar quais deles interferem na determinação da classificação por estação de coleta das amostras dos córregos Cerradinho e Jaboticabal (Tabela 4).

Tabela 4. Classificação das águas dos córregos Cerradinho e Jaboticabal, nas estações de amostragem, em função do parâmetro e da Resolução CONAMA 20/86, de maio/1999 a abril/2000, Jaboticabal-SP

\begin{tabular}{|c|c|c|c|c|c|c|c|c|c|}
\hline \multirow{2}{*}{$\begin{array}{l}\text { Estação de } \\
\text { amostragem }\end{array}$} & \multicolumn{8}{|c|}{ Parâmetro } & \multirow[b]{2}{*}{ Classe } \\
\hline & $\mathrm{pH}$ & $\mathrm{OD}$ & $P_{\text {total }}$ & Nitrato & Nitrito & DBO & $\begin{array}{l}\text { Coli } \\
\text { total }\end{array}$ & $\begin{array}{l}\text { Coli } \\
\text { fecal }\end{array}$ & \\
\hline $\mathrm{C} 1$ & $\begin{array}{c}1 \mathrm{a} \\
4\end{array}$ & 3 & --- & 1 a 4 & 1 a 4 & 1 & 4 & 2 & 4 \\
\hline $\mathrm{C} 2$ & $\begin{array}{c}1 \mathrm{a} \\
4\end{array}$ & 3 & --- & 1 a 4 & 1 a 4 & 3 & 4 & 4 & 4 \\
\hline J1 & --- & 3 & 1 a 3 & $1 \mathrm{a} 4$ & 1 a 4 & 1 & 1 & 1 & 3 \\
\hline $\mathrm{J} 2$ & --- & 3 & --- & $1 \mathrm{a} 4$ & 1 a 4 & 1 & 4 & 4 & 4 \\
\hline$\overline{\mathrm{J} 3}$ & $\begin{array}{c}1 \mathrm{a} \\
4\end{array}$ & 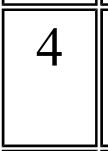 & --- & 1 a 4 & 1 a 4 & 3 & 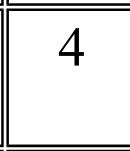 & 4 & 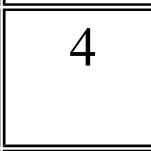 \\
\hline $\mathrm{JC} 1$ & $\begin{array}{c}1 \mathrm{a} \\
4 \\
\end{array}$ & 3 & --- & 1 a 4 & 1 a 4 & 3 & 4 & 4 & 4 \\
\hline JC2 & $\begin{array}{c}1 \mathrm{a} \\
4\end{array}$ & $\mid---$ & ב--- & 1 a 4 & 1 a 4 & 4 & 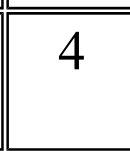 & 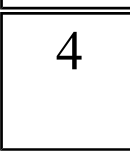 & 4 \\
\hline
\end{tabular}

Nas estações $\mathrm{J} 1$ e $\mathrm{J} 2$ foram encontrados valores de $\mathrm{pH}$ abaixo de 6,0 , portanto fora do limite determinado pela Resolução CONAMA 20/86 para os rios de Classe 1 à 4 ( $\mathrm{pH}$ entre 6,0 e 9,0); nas demais estações os valores permaneceram entre 6,0 e 7,1 . 
No parâmetro OD, o Córrego Cerradinho é Classe 3 e o Jaboticabal: à montante da área urbanizada é Classe 3 , à confluência com o Cerradinho é Classe 4, após receber o Cerradinho é Classe 3 e à jusante da área urbanizada não há enquadramento.

No parâmetro $\mathrm{P}_{\text {total }}$, a estação $\mathrm{J} 1$ foi a única cujos teores em todos os meses ficaram abaixo do limite de $25 \mathrm{~m}$ g. $\mathrm{L}^{-1}$ determinado para as Classes de 1 a 3.

No parâmetro nitrato, as águas de Classes 1 a 4 podem apresentar teor de até $10 \mathrm{mg} . \mathrm{L}^{-1}$, sendo também o limite permitido em água potável. Nesse parâmetro as águas analisadas enquadram-se nessas especificações pois o maior teor foi $7,8 \mathrm{mg} . \mathrm{L}^{-1}$.

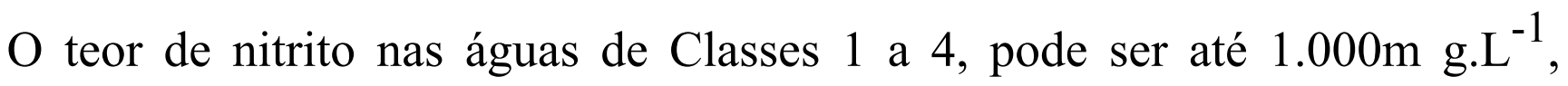
inclusive é o teor limite permitido em água potável. No período estudado, o teor máximo encontrado foi $219 \mathrm{~m} \mathrm{g.L^{-1 }}$, portanto dentro dessas especificações.

Os teores de DBO nas estações à montante da área mais urbanizada $(\mathrm{C} 1, \mathrm{~J} 1 \mathrm{e}$ $\mathrm{J} 2$ ) foram de até $3 \mathrm{mg} . \mathrm{L}^{-1}$, enquadrando-se na Classe 1 ; na região próxima à confluência dos córregos (C2, J3 e JC1) ocorreram meses em que o teor ficou entre 5,0 e 6,9mg. $\mathrm{L}^{-1}$, enquadrando-se na Classe 3, exceto em janeiro na $\mathrm{C} 2\left(19,2 \mathrm{mg} . \mathrm{L}^{-1}\right)$; e à jusante da emissão dos esgotos (JC2) os teores foram maiores que $21 \mathrm{mg}^{-\mathrm{L}^{-1}}$ enquadrando-se na Classe 4.

Os valores de NMP de CT na cabeceira do Córrego Jaboticabal (J1) foram de até $1,2 \times 10^{2} .100 \mathrm{~mL}^{-1}$, enquadrando-se na Classe 1 e os valores nas outras estações foram superiores a $4,3 \times 10^{4} .100 \mathrm{~mL}^{-1}$, enquadrando-se na Classe 4 .

Os valores de NMP de CF na cabeceira do Córrego Jaboticabal (J1) foram de até $1.100 \mathrm{~mL}^{-1}$ enquadrando-se na Classe 1 , na $\mathrm{C} 2$ foram de até $4,3 \times 10^{2} .100 \mathrm{~mL}^{-1}$ enquadrando-se na Classe 2 e nas demais estações foram superiores a $9,9 \times 10^{3} .100 \mathrm{~mL}^{-1}$ enquadrando-se na Classe 4.

Na Figura 1 pode-se observar a classificação das estações de amostragem e cursos d'água estudados, sendo que em função da Resolução CONAMA 20/86: a estação $\mathrm{J} 1$ apresenta um parâmetro $(\mathrm{pH})$ cujo valor enquadra em Classe superior à de número 3 ; a $\mathrm{C} 1$ apresenta dois $\left(\mathrm{P}_{\text {total }}\right.$ e CT); a C2 e a JC1 apresentam três $\left(\mathrm{P}_{\text {total }}\right.$, CT e CF); a J2 apresenta quatro $\left(\mathrm{pH}, \mathrm{P}_{\text {total }}\right.$, $\mathrm{CT}$ e $\left.\mathrm{CF}\right)$; a J3 também apresenta quatro $\left(\mathrm{P}_{\text {total }}, \mathrm{CT}, \mathrm{CF}\right.$ e $\mathrm{OD})$; e a JC2 apresenta cinco ( $\mathrm{P}_{\text {total }}, \mathrm{CT}, \mathrm{CF}, \mathrm{OD}$ e DBO). 
Dos parâmetros hídricos analisados o $\mathrm{P}_{\text {total }}$, os CT e os CF contribuíram com maior número de vezes para inviabilizar o uso das águas na Classe 3 (destinadas ao abastecimento doméstico após tratamento convencional, à irrigação de culturas arbóreas, cerealíferas e forrageiras e à dessedentação de animais).

Se a perspectiva for o enquadramento das águas na Classe 2 (destinadas ao abastecimento doméstico após tratamento convencional, à proteção das comunidades aquáticas, à recreação de contato primário, à irrigação de plantas, hortaliças e frutíferas e na agricultura) também é necessário adequar os parâmetros de OD e DBO.

A estação J1, exceto nos parâmetros de $\mathrm{OD}$ e $\mathrm{pH}$, apresenta características de Classe 1. No pH, a provável interferência do solo pode dificultar seu enquadramento.

\section{Proposta de Ações Mitigadoras}

Considerando que o Plano Diretor do Município de Jaboticabal (JABOTICABAL, 1994) foi revisto com o objetivo de melhorar a qualidade de vida de seus habitantes mediante o direito ao meio ambiente não degradado, o uso e ocupação do solo à capacidade de sustentação ambiental e à incorporação de princípios de desenvolvimento sustentável nas políticas públicas (JABOTICABAL, 2000), os resultados desta pesquisa permitem propor para os córregos Cerradinho e Jaboticabal:

- Implantar um plano de monitoramento contínuo da qualidade da água dos rios;

- Implantar estações hidrométricas para conhecimento adequado do regime de suas vazões;

- Executar o tratamento do esgoto domiciliar e industrial, impedindo seu despejo "in natura";

- Impedir o lançamento de esgoto clandestino humano ou animal nos córregos;

- Manter um sistema eficiente de limpeza urbana, impedindo a ação impactante do escoamento superficial, seja de lixos domiciliares ou de resíduos sólidos de diversas origens;

- Fiscalizar efetivamente os estabelecimentos e domicílios que utilizam produtos químicos em quantidade impactante, inclusive em limpeza e que são direcionados para as rede de esgoto ou vias públicas;

- Fiscalizar as práticas rurais, recomendando práticas conservacionistas do solo, controle no uso de adubação e de defensivos agrícolas e no manejo de criações;

- Cumprir a legislação referente à proteção de mananciais, reflorestando as nascentes e implantando matas ciliares;

- Recuperar a estética paisagística dos córregos, implementando atrativos que valorizem seu potencial hídrico para lazer (pesca e turismo) e diminuição da poluição visual; 
- Fomentar práticas que facilitem a infiltração da água no solo em áreas públicas e particulares, inclusive residenciais, minimizando os efeitos do escoamento superficial e permitindo o abastecimento regular dos mananciais e lençol freático;

- Implantar programas de educação ambiental que resgatem os valores históricos dos cursos d'água urbano e que desperte na população sua participação como agente responsável pela recuperação da qualidade ambiental mediante a incorporação dos princípios de desenvolvimento sustentável das políticas públicas;

- Implantar programa de irrigação agrícola, aproveitando o solo como depurador hídrico e a água residuária como fonte hídrica e de nutrientes para as plantas;

- Fomentar a parceria entre a Prefeitura de Jaboticabal e a UNESP, no desenvolvimento de pesquisas de interesse mútuo, valendo-se da importância e da posição estratégica da área de domínio dessas instituições em relação à bacia hidrográfica do Córrego Jaboticabal;

- Desenvolver um plano integrado de manejo hídrico na bacia hidrográfica do Córrego Jaboticabal, minimizando ou até eliminando sua contribuição negativa às águas do Córrego Rico e, por sua vez, do Rio Mogi-Guaçu.

\section{CONCLUSÕES}

- O monitoramento da qualidade hídrica dos córregos Jaboticabal e Cerradinho, detectou a intensidade com que poluentes químicos e biológicos estão presentes nos pontos de amostragem, sendo que os parâmetros DQO, nitrito, nitrato, $\mathrm{P}_{\text {total }}, \mathrm{DBO}$, coliformes totais e coliformes fecais: estão melhores nas águas do Córrego Cerradinho em relação ao Córrego Jaboticabal; estão melhores nas estações à montante e piores nas à jusante da cidade.

- Tanto no Córrego Cerradinho quanto no Córrego Jaboticabal, houve aumento da poluição hídrica da nascente à foz.

- A prática isolada da coleta de esgoto não foi suficiente para se considerar despoluído os Córregos Jaboticabal e Cerradinho.

- Dos parâmetros analisados o $\mathrm{P}_{\text {total }}$, os coliformes totais e os coliformes fecais, foram os que mais contribuíram para inviabilizar o uso das águas na Classe 3 e se a perspectiva for o enquadramento das águas na Classe 2, também é preciso adequar os parâmetros de OD e DBO.

- É imprescindível desenvolver um plano integrado de manejo hídrico na bacia hidrográfica do Córrego Jaboticabal, minimizando ou até eliminando sua contribuição negativa às águas do Córrego Rico e, por sua vez, às do Rio MogiGuaçu. 
ADAMS, V.D. Water \& wastewater examination manual. Chelsea: Lewis Publishers, 1990. 247p.

AMERICAN PUBLIC HEALTH ASSOCIATION - APHA. Standard methods for examination of water and wastewater. $19^{\text {th }}$. ed. Washington: EPS Group, 1995. p.1.1-9.68.

BATALHA, B.H.L. Ameaça microscópica na água potável. Ciência Hoje, Rio de Janeiro, v.25, n.145, p.29-34, 1998.

BENINCASA, M. Estudo hidrológico preliminar da região de Jaboticabal. 1971. 88f. Dissertação (Mestrado em Meteorologia) - Faculdade de Ciências Agrárias e Veterinárias, Universidade Estadual Paulista, Jaboticabal, 1971.

BRAILE, P.M.; CAVALCANTI, J.E.W.A. Manual de tratamento de águas residuárias industriais, SP, Brasil. São Paulo: CETESB, 1979. 764p.

CAMARGO, A.F.M. Poluição das águas: esgotos sanitários domésticos e industriais. Rio Claro, 1997. 22p. Apostila.

CAMARGO, A.F.M.; BINI, L.M.; SCHIAVETTI, A. Avaliação dos impactos provocados pelas descargas de esgotos orgânicos em alguns corpos d'água do município de Rio Claro. Oecologia Brasiliensis, Rio de Janeiro, v.2, p.395-406, 1995.

CENTURION, J.F. Caracterização e classificação dos solos da Faculdade de Ciências Agrárias e Veterinárias de Jaboticabal. 1998. 85f. Tese (Livre Docência em Pedologia) - Faculdade de Ciências Agrárias e Veterinárias, Universidade Estadual Paulista, Jaboticabal, 1998.

COMPANHIA DE TECNOLOGIA DE SANEAMENTO AMBIENTAL - CETESB. Relatório de qualidade das águas interiores do Estado de São Paulo - 1993. São Paulo, 1994. 225p.

CONSELHO NACIONAL DO MEIO AMBIENTE - CONAMA. Resolução CONAMA n²0: classificação das águas do território nacional. Brasília: Imprensa Oficial, 1986. p.43-53.

DAMASCENO, S.; CAMPOS, J.R. Potencial do reuso de efluente de sistema de lagoas de estabilização na irrigação. Revista Irriga, Botucatu, v.5, n.1, p.44-51, 2000.

GIOMETTI, A.B. R. Diagnóstico e prognóstico ambiental como subsídio para a gestão da Bacia do Ribeirão dos Pinheirinhos ou da Cachoeira - SP. 1998. 341f. Tese (Doutorado em Geografia) - Instituto de Geociências e Ciências Exatas, 
Universidade Estadual Paulista, Rio Claro, 1998.

GRASSI, M.T.; JARDIM, W. de F. Ozonização de águas: aspectos químicos e toxicológicos. Revista DAE-SABESP, São Paulo, n.173, set/out, p.1-6, 1993.

INSTITUTO BRASILEIRO DE GEOGRAFIA E ESTATÍSTICA - IBGE. Censo Demográfico São Paulo 2000: dados preliminares. Rio de Janeiro, 2000.

INSTITUTO GEOGRÁFICO E CARTOGRÁFICO - IGC. Coordenadoria de Planejamento Regional. Plano Cartográfico do Estado de São Paulo: 1991. São Paulo: Secretaria de Planejamento e Gestão, 1991.

JABOTICABAL. Lei Complementar n⿳19, de 08 de julho de 1994: Plano Diretor do Município de Jaboticabal. Jaboticabal, 1994. 15p.

JABOTICABAL. Perfil do Município de Jaboticabal/SP. Jaboticabal: Caixa Econômica Federal, 1999. 73p.

JABOTICABAL. Ante-Projeto de Lei Complementar: revisão do Plano Diretor de Jaboticabal. Jaboticabal, 2000. 173p.

JOLLY, A.B. Conheça a vegetação brasileira. São Paulo: Polígono, 1970. 181p.

LANDIM, P.M.B. Recursos naturais não renováveis e desenvolvimento sustentável. In: MARTOS, H.L., MAIA, N.B. (Coord.). Indicadores ambientais. Sorocaba: Bandeirantes Indústria Gráfica, 1997. p.9-13.

MALAVOLTA, E.; VITTI, G.C.; OLIVEIRA, S.A. de. Avaliação do estado nutricional das plantas: princípios e aplicações. Piracicaba: Associação Brasileira para Pesquisa da Potassa e do Fosfato, 1989. p.201.

MARGALEF, R. Limnologia. Barcelona: Omega, 1983. 1100p.

MATHEUS, C.E.; MORAES, A.J. de; TUNDISI, T.M.; TUNDISI, J.G. Manual de análises limnológicas. São Carlos: Centro de Recursos Hídricos e Ecologia Aplicada, USP, 1995. 62p.

MOTA, S. Saneamento. In: ROUQUAYROL, M.Z. Epidemiologia \& saúde. 4. ed. Rio de Janeiro: MEDSI, 1993. cap.12, p.343-364.

PALMA-SILVA, G.M. Diagnóstico ambiental, qualidade da água e índice de depuração do Rio Corumbataí-SP. 1999. 155f. Dissertação (Mestrado em Manejo Integrado de Recursos) - Centro de Estudos Ambientais, Universidade Estadual Paulista, Rio Claro, 1999. 
PINTO, A.L. Saneamento básico e suas implicações na qualidade das águas subterrâneas da cidade de Anastácio - MS. 1998. 175f. Tese (Doutorado em Geociências e Meio Ambiente) - Instituto de Geociências e Ciências Exatas, Universidade Estadual Paulista, Rio Claro, 1998.

SECRETARIA DE ESTADO DO MEIO AMBIENTE - SMA. Uma nova política de mananciais: diretrizes e normas para a proteção e recuperação das bacias hidrográficas dos mananciais de interesse regional do Estado de São Paulo. São Paulo, 1997. 24p.

SECRETARIA DE ESTADO DE RECURSOS HÍDRICOS SANEAMENTO E OBRAS - SRHSO. Comitês de bacia hidrográfica. São Paulo: DAEE, 1998.

SNEATH, P.H.A., SOKAL , R.R. Numeral taxonomy. San Francisco: W. H. Freeman, 1973. 573p.

TUNDISI, J.G. Limnologia no século XXI: perspectivas e desafios. São Carlos: Suprema Gráfica e Editora, IIE, 1999. 24p.

VALERI, S.V.; MENEZES, J.M.T. Biodiversidade e potencialidade de sistemas agroflorestais na região de Jaboticabal, Estado de São Paulo. In: CONGRESSO BRASILEIRO DE SISTEMAS AGROFLORESTAIS: manejando a biodiversidade e compondo a paisagem rural, 3., 2000, Manaus. Anais... Manaus: Imprensa Universitária, 2000. p.63-65. 